\title{
Analysis on the Dilemma and Coping Strategies of the People-to-People Bond in Lancang-Mekong Basin*
}

\author{
Yuanshuai Niu \\ Development and Research Center \\ Yunnan Normal University \\ Kunming, China 650500
}

\begin{abstract}
The globalization and integration of the world economy are developing rapidly and irresistibly. Every country does not want to be marginalized. People in the LancangMekong basin drank the same river water. In this respect, it has the advantages of close geographical location, close personal relationship, close cultural relationship, and good business relationship. At the same time, it is also affected by various factors such as economic differences, policy implementation, cultural conflicts, value orientations, and great power games among the six countries in the basin. This article describes the historical basis, evolution process, realistic conditions, and driving factors of people-to-people bond in Lancang-Mekong basin, analyzes the plight of people-to-people bond in Lancang-Mekong basin, and finally proposes coping strategies.
\end{abstract}

Keywords-Lancang-Mekong basin; people-to-people bond; coping strategies

\section{INTRODUCTION}

The Lancang-Mekong River is the sixth largest river in the world, the third largest river in Asia, and the largest river in Southeast Asia. It originates from the Ganguori Peak in the Tanggula Mountains of Qinghai Province, and flows from north to south through three provinces or regions of Qinghai, Tibet, and Yunnan, and five Southeast Asian countries, Myanmar, Laos, Thailand, Cambodia, Vietnam. It has a total length of 4,909 kilometers, a total area of 810,000 square kilometers, and a total population of 71.87 million. It is known as the "Danube River in the East". Since ancient times, the country of Lancang-Mekong basin has the same mountains and rivers, the same ethnic roots and the same culture. In the long history of development, they have a long history, deep and extensive economic and human relations. Lancang-Mekong basin has created a splendid civilization and accumulated a heavy heritage in the long-term historical development process, which is the historical witness of the

*Fund: National Social Science Fund (19BMZ071). Research on the historical evolution and driving mechanism of people-to-people bond in Lancang-Mekong basin since reform and opening up; Social Science Planning Project of Yunnan Province (YB2018035). Phased research results of research to promote the deep integration of Yunnan border areas into the "Belt and Road" initiative.

Chinese library classification number: G115; Document code: A spirit of the Silk Road and people-to-people bond, providing irreplaceable cultural wealth for human development and progress. In the context of accelerating the "the Belt and Road initiative", in view of the rising trend of unilateralism, protectionism, and nationalism, people in the LancangMekong basin need to further develop the advantages of people-to-people bonds, geographical proximity, blind date, literary affinity, and commercial fusion. It is important to overcome various factors such as economic differences, policy implementation, cultural conflicts, value orientations, and great power games among the six countries in the basin, to systematicially deconstruct the plight of people-to-people bond in Lancang-Mekong basin, explore coping strategies for people-to-people bond in Lancang-Mekong basin.

\section{REVIEW OF RELATED RESEARCH LITERATURE}

The Lancang-Mekong basin is rich in historical and cultural resources, and it can learn from history and develop industries (Ji Pimisa, 1976; Fu Guangyu et al., 1995; Pan Jihua, 2012; Li Xiaomei et al., 2016). The Lancang-Mekong basin has a long ethnic history, which gave birth to the unique and close cultures of the Lancang-Mekong basin. The origin, formation, change, and evolution of the various ethnic groups in the river basin have their own characteristics and many common features (Fang Guoyu, 1958; Milton Osborne, 2000; He Ping, 2005; C. Hart Schaaf, 2016). China and the Mekong Basin countries have had close trade, cultural, and political ties both historically and today, and have extensive cooperation in the inheritance and innovation of national cultures (Zhao Shilin, 2001; Zhang Jianxin, 2009; Li Yiping, 2015; Shao Erqing, 2016; Wei Danfang, 2017; Yin Jun, 2017).

For a long time, the six countries of Lancang-Mekong basin and related countries have carried out a lot of work around the people-to-people bonds of the basin. The cooperative development of the Lancang-Mekong basin originated in the 19th century, and the first stage was before the early period of 1947, mainly from the economic and colonial interests of Britain and France in the Asian region (Nguyen Thi Dieu, 1999; Huang Feng, 2016). The second stage is from 1947-1975, the origin and development period of the Mekong development mechanism (Franklin P. Huddle, 
1972; Zheng Xianwu, 2016). The third stage is from 1976 to the present. With the end of the Cold War, the situation in Southeast Asia has stabilized, and various cooperation mechanisms have emerged around the Mekong (Zhang Yu, 2017; Feng Shun, 2017).

Promoting Lancang-Mekong cooperation is a concrete practice proposed by General Secretary $\mathrm{Xi}$ Jinping to promote the construction of a community with a shared future. After the 19th CPC National Congress, General Secretary $\mathrm{Xi}$ Jinping chose Vietnam and Laos for two Lancang-Mekong basin countries on his first visit. General Secretary Xi Jinping emphasized at the second "the Belt and Road" International Cooperation Summit Forum that the key to co-construction of the "Belt and Road" is interconnection. Lancang-Mekong basin's largest trading partner in countries other than Laos is China (Liu Zhi. 2019). Lancang-Mekong basin countries have common needs for cooperation in industrialization, infrastructure construction, upgrading of industrial structure, acceleration of agricultural modernization, and development of tourism (Bi Shihong, 2013; Liu Yamin, 2018). The deep friendship of "drinking together a river of water, and mutual affection" is the cultural cornerstone of the people-to-people bond in LancangMekong basin. Humanistic communication is a prerequisite for realizing a people-to-people bond in the LancangMekong basin, and an important basis for building a community of destiny in the Lancang-Mekong basin (Frankim P. Huddle, 1972; Le Thi Tuyet, 1973; Guo Yanjun, 2011; Lu Xing, 2016). These countries strengthen the security dialogue through the community of responsibility, promote strategic mutual trust, and maintain peace and stability in the Lancang-Mekong basin (Xiang Qun, 2010; Liu Zhi, 2015; Shi Qiang, 2017; Sun Xuehua, 2018), vigorously promote economic and trade cooperation through a community of interests, consolidate the foundation of common interests, and promote the prosperity and development of the Lancang-Mekong basin (Chen Wei, 2013; Zhang Yang, 2016), actively promote the construction of people's livelihood through the humanities community, strengthen people-friendly exchanges, and promote the harmonious coexistence of Lancang-Mekong basin (Satoru Akiba, 2010; Liu Zhi, 2000; Zhu Zhenming, 2004; Wen Shuhui, 2006; Zhao Shulan, 2011). Finally, people-to-people bond construction will fundamentally eliminate the problems and obstacles of sustainable and healthy development of Lancang-Mekong basin (Li Guangyi, 2014; Li Chang, 2018).

In view of this, this article analyzes the research status and frontier issues of people-to-people bond in LancangMekong basin in China and foreign countries, and analyzes and summarizes the overall geopolitical environment of Lancang-Mekong basin, and then explores the dilemma faced by people-to-people bonds, and finally proposes countermeasures, with a view to promoting the "the Belt and Road initiative" and Lancang-Mekong cooperation to achieve new progress.

\section{AN ANALYSIS OF THE GEOPOLITICAL ENVIRONMENT OF LANCANG-MEKONG BASIN}

The Lancang-Mekong River is the common wealth that nature has given us. It is a natural link connecting the six countries in the river basin and an important source for maintaining regional peace and promoting common development. The Lancang-Mekong basin is located at the junction of East Asia, Southeast Asia, and South Asia, with geographical convenience and outstanding strategic advantages (Jeffrey Parker, 2003; Giovanni Arigi, 2006; Lu Guangsheng, 2017). The Lancang-Mekong basin is closely linked to drinking a river of water, with a shared destiny, common cultural roots and similar values. Traditional friendship has been passed down from generation to generation (Mussay Hiebekt, 1991; Pu Huiyan et al., 2001; Chang Wei, 2017). Lancang-Mekong basin is connected by mountains and rivers, similar in culture, and frequent cultural exchanges. Cross-border personnel exchanges have a solid public opinion foundation, and social and cultural cooperation has played a leading role in promoting peopleto-people bond in Lancang-Mekong basin (Mussay Hiebekt, 1991; Pu Huiyan et al., 2001; Chang Wei, 2017). LancangMekong basin is a natural partner of countries with outstanding economic relevance and complementary resources. Creating the Lancang-Mekong basin economic development belt will enable complementary advantages and common development (Li Keqiang, 2018; Wang Yi, 2018).

The Lancang-Mekong basin has complex regional characteristics, changing natural conditions, relatively backward economic development, a less optimistic security situation, and more complicated personnel exchanges. Since the Second World War, the Mekong basin has become a "fighting place for soldiers" and faces the trend of "Finance \& Economy" (Ma Yan. 2014; Liu Yamin. 2018). Hidden behind it is extreme sensitivity and worry about the power of great powers (C. Hart Schaaf, 1963; Lalita Prasad Singh, 1966; Eugene R. Black, 1969; Wu Shishao, 2011; Luo Yifu, 2018). In recent years, especially since China proposed to establish a Lancang-Mekong dialogue and cooperation mechanism in November 2014, more and more scholars have begun to pay attention to the construction of people-topeople bond in Lancang-Mekong basin.

The "the Belt and Road initiative" is aimed at focusing on interconnection and interoperability, deepening pragmatic cooperation, and jointly coping with various risks and challenges facing humankind to achieve mutual benefit, winwin and common development. The Lancang-Mekong basin is currently facing the challenge of rising unilateralism and nationalism (Deng Yunfei, 2017; Ma Yong, 2017). The Lancang-Mekong basin, which develops and thrives on water, needs to build a strong Lancang-Mekong destiny community (Li Keqiang, 2016; Xing Wei, 2016; Zhong Sheng, 2017; Shao Xianping, 2019). After years of integration and development, Lancang-Mekong cooperation has reached a certain level. Against the background of the intensified game of big powers and the intricate international relations, the existing driving mechanism presents a problem of insufficient motivation in improving the level of regional cooperation. Moreover, it cannot effectively solve the 
differences in history, culture, religion, and social customs. China advocates the creation of a "Lancang-Mekong culture" where civilizations learn from each other beyond conflicts of civilizations and coexistence of civilizations. Scholars from the Mekong countries are more inclined to describe the cultural cooperation between the Lancang-Mekong society as "repairing the image" and "cultural exchange". At the same time, there are controversial territorial issues between some countries in the Lancang-Mekong basin. The cultural collision caused by these factors has added uncertain factors to people-to-people bonds, and has brought some resistance to the sustainable development of social and cultural cooperation among countries in the Lancang-Mekong basin.

\section{Action Bias Caused by Value Orientation}

People's value orientation caused by cultural differences also varies. Lancang-Mekong basin countries that have always been regarded as indisputable, indifferent, quiet, and extremely happy because of religion and culture, have experienced a decline in happiness rankings in recent years. Therefore, there is an urgent need to strengthen public guidance to the Lancang-Mekong basin countries. For the popular culture and grassroots culture that ordinary people love to see, further inheritance and innovation are needed. It is necessary to establish a comprehensive, systematic and correct understanding of the people-to-people bond in Lancang-Mekong basin, and to enhance the radiative power and penetration of value orientation through "ground gas" communication activities.

\section{E. External Effects Brought by Superpower Games}

For a long time, the United States and Japan have operated in the Lancang-Mekong basin for many years. In terms of social and cultural cooperation, they have expanded new segments, accumulated new resource advantages, and accelerated the coverage of different groups, especially youth groups, in Mekong countries. At the same time, South Korea, India and other countries followed closely, and the influence of countries outside the basin on the Lan Mae Basin continued to increase. In addition to advocating ideology and serving their own diplomatic needs, Western countries' social and humanistic cooperation also from time to time targets third-party and hotspot issues, and encourages the personnel networks they build to coordinate their foreign policies at important time points. The extreme nationalist sentiment in Lancang-Mekong basin-related countries was caused to "spill out", which brought uncertainties to the mutual relations and regional stability among Lancang-Mekong basin countries.

\section{Coping StRategies OF PEOPLE-TO-PEOPLE BOND IN LANCANG-MEKONG BASIN}

\section{A. Consolidating the Foundation of People-to-people Bond in Lancang-Mekong Basin Through Economic-drive}

Economy is the foundation and top priority, and development is the key to solving all problems. Promoting people-to-people bond in Lancang-Mekong basin needs to make full use of the characteristics of the six countries of the
Although the six countries in the Lancang-Mekong basin are geographically close and related, they also have certain 
Lancang-Mekong basin with high economic correlation and complementarity, and to tap the endowment of the LancangMekong river golden channel resources, and to strive to create an open and inclusive Lancang-Mekong basin economic development belt that is innovative, efficient, collaborative, win-win, beautiful, and harmonious. Under the framework of the Lancang-Mekong basin economic development zone, strengthening infrastructure construction, promoting industrial development transformation, accelerating the development of cross-border e-commerce, improving the level of network connectivity, and comprehensively driving the development of the LancangMekong basin hinterland. Through the economic drive, the people of Lancang-Mekong basin are seeking win-win cooperation, and the region has realized the improvement of the quality and efficiency of economic development in the whole basin.

\section{B. Consolidating the Guarantee of People-to-people Bond in Lancang-Mekong Basin Through Policy-driving}

Policy is the cornerstone and institutional guarantee. It is necessary to actively coordinate the development strategies of the six countries of the Lancang-Mekong basin and formulate policies and measures consistent with the actual situation of the Lancang-Mekong basin. It is necessary to guide the practical development of people-to-people communication through policy drive, to complement the advantages of the Lanmei River Basin, and to solve the original imbalance, uncoordinated, and unsustainable development problems of the Lancang-Mekong basin. Efforts should be made to promote the cooperation process of Lancang-Mekong basin, and provide convenient and liberalized measures for personnel exchanges, material transportation, and investment promotion in LancangMekong basin. To build a more complete Lancang-Mekong basin industrial chain and value chain, to achieve coordinated development and people-to-people bonds based on the rational flow of production factors and the optimal allocation of resources in the Lancang-Mekong basin.

\section{Consolidating the Premise of People-to-people Bond in Lancang-Mekong Basin Through Cultural-drive}

People-to-people bonds are valuable for understanding and tolerance in culture. The construction of the LancangMekong basin community of destiny requires continuous promotion of cultural exchanges in harmony in diversity and subtle influence. On the one hand, cultural exchanges such as cultural visits, cultural activities, and cultural cooperation can be used to subtly promote the spiritual communication in Lancang-Mekong basin. On the other hand, people-to-people bond in Lancang-Mekong basin can also be promoted through resource development, economic and trade exchanges, and mutually beneficial cooperation in the fields of science and technology, humanities, education, medical treatment, and health, jointly seeking a larger common divisor of cultural cognition, and realize intercultural understanding, identity, and consensus. Eventually, the distance between people in different areas of the LancangMekong basin was brought closer, and dialogue and communication were used to advocate the shelving and narrowing differences, tolerance and reference of different Lancang-Mekong basins.

\section{Consolidating the Goal of People-to-people Bond in Lancang-Mekong Basin Through Symbiotic Drive}

With the development of the global economy, the countries of the Lancang-Mekong basin are interdependent, share weal and woe, and have achieved mutual benefits and win-win results in politics, economy and culture. In the new era, it is necessary for the six countries in the basin to take advantage of the current situation and promote the establishment of a Lancang-Mekong basin community based on the principles of mutual consultation, co-construction and sharing, based on mutual trust, mutual benefit, and mutual tolerance, and with visions of interests, responsibilities and destiny, advancing the sustainable development of LancangMekong basin by symbiotic drive.

\section{E. Consolidating the Mechanism of People-to-people Bond in Lancang-Mekong Basin Through Symbiotic Platform- drive}

The establishment of a people-to-people bond in Lancang-Mekong basin communication platform can start from government communication platforms, enterprise communication platforms, and private communication platforms, paying attention to the interactivity, participation and publicity of the people in Lancang-Mekong basin. At the government level, Lancang-Mekong basin countries can take turns to host people-to-people bond exchanges through public diplomacy platforms to promote government-topeople people-to-people bond in Lancang-Mekong basin. At the enterprise level, bilateral and multilateral win-win situations can be promoted through economic and trade platforms. At the private level, the friendly development of people-to-people bond in Lancang-Mekong basin can be promoted through friendly exchanges such as tourism, visiting relatives and friends, and cultural exchanges, making the win-win cooperation truly reach the hearts of the people and benefiting the people of Lancang-Mekong basin.

\section{CONCLUSION}

The economy of the Lancang-Mekong basin has strong complementary advantages. The people-to-people bond in Lancang-Mekong basin meets the common needs of the six countries in the basin. The co-construction of the LancangMekong basin community of national destiny is a new model of "South-South cooperation" for developing countries to promote globalization and regionalization. In the new era, people-to-people bond in Lancang-Mekong basin should take advantage of geographical similarity, personal relationship, cultural connection, and commercial integration, avoid the impact of various factors such as economic differences, policy implementation, cultural collision, value orientation, and superpower games in the Lancang-Mekong basin, grasp the historical basis, evolution process, realistic conditions, driving factors, and other laws of people-topeople bond in Lancang-Mekong basin, and create a new situation for the community of national fate in LancangMekong basin. 


\section{REFERENCES}

[1] Liu Chang. Social and cultural cooperation in Lancang-Mekong basin: the status quo and improvement ways [J]. International Studies, 2018, 6: 87-103 + 119. (in Chinese)

[2] Chen Lihui, Zeng Zungu, He Daming. Conflicts of Interest and Coordination of Their Relationships in the Development of International River Basins: Taking the Lancang River-Mekong River as an Example [J]. World Regional Studies, 2003, 3: 71-78. (in Chinese)

[3] Zhen Weiran, Liu Hongliang. "People-to-people bond": a community vision based on cultural exchanges: the dilemma and cracking of cultural identity in the "the Belt and Road" [J]. Publishing Research, 2018,3: 5 -10. (in Chinese)

[4] Liu Yamin. An empirical analysis of the current status of People-topeople bonds between China and the Mekong countries - with the background of Lancang-Mekong cooperation [D]. Guangxi University for Nationalities, 2018: 1-61. (in Chinese)

[5] Liu Zhi, Lu Guangsheng. Lancang-Mekong cooperation blue book: Lancang-Mekong cooperation development report [M]. Social Sciences Academic Press (CHINA), 2019: 24-125. (in Chinese) 